\title{
Recurrent Childhood Diffuse Astrocytoma
}

National Cancer Institute

\section{Source}

National Cancer Institute. Recurrent Childhood Diffuse Astrocytoma. NCI Thesaurus.

Code C115360.

The reemergence of diffuse astrocytoma in childhood after a period of remission. 